Doctors reported patients and colleagues to be their main sources of recognition in the workplace. We hypothesise that perceived recognition increases self-esteem and provides emotional support, which may, in turn, compensate for the low financial recognition. Psychiatry has historically been a prestigious specialty in Argentina. It will be interesting to test formally the hypothesis whether its prestige is related to the subjective satisfaction of practitioners.

A study evaluating job burnout in a European Union country used several structured assessments. It found that that a low level of job satisfaction was the variable that most predicted burnout (Bressi et al, 2009). Our group is currently researching to what extent burnout is predicted by emotional exhaustion, as opposed to lack of job satisfaction (Wolfberg et al, 2005).

In summary, this study was the first to have addressed in Argentina questions about psychiatrists' job satisfaction and related aspects of their working lives. It surveyed a large sample, and provided data to advance research, in a country rich in human resources, and a system that needs a more rigorous research policy.

\section{Acknowledgements}

The authors deeply thank all members of the Faculty of Prevention in Psychiatry, Association of Argentinian Psychiatrists, who took an active part in this project.

\section{References}

Bressi, C., Porcellana, M., Gambini, O., et al (2009) Burnout among psychiatrists in Milan: a multicenter survey. Psychiatric Services, 60, 985-988.

Cordoba, R. N., Cano, J. F., Alzate, M., et al (2009) [The Latin American psychiatrist: profile and degree of satisfaction with the specialty.] Actas Españolas de Psiquiatría, 37, 9-16.

Ellencweig, N., Weizman, A. \& Fischel, T. (2009) Factors determining satisfaction in psychiatry training in Israel. Academic Psychiatry, 33, 169-173.

Fischer, J., Kumar, S. \& Hatcher, S. (2007) What makes psychiatry such a stressful profession? A qualitative study. Australasian Psychiatry, 15, 417-421.

Gomez-Restrepo, C., Gil Laverde, F., Diaz-Granados, N., et al (2003) El perfil del medico psiquiatra colombiano. [Stereotype of the Colombian psychiatrist.] Revista Colombiana de Psiquiatría, 32, 325-340.

Inoue, M., Tsukano, K., Muraoka, M., et al (2006) Psychological impact of verbal abuse and violence by patients on nurses working in psychiatric departments. Psychiatry and Clinical Neurosciences, 60, 29-36.

Kazantzis, N., Calvert, S. J., Orlinsky, D. E., et al (2010) Professional development perceptions and activities of psychiatrists and mental health nurses in New Zealand. New Zealand Medical Journal, 123, 24-34.

Korkeila, J. A., Toyry, S., Kumpulainen, K., et al (2003) Burnout and selfperceived health among Finnish psychiatrists and child psychiatrists: a national survey. Scandinavian Journal of Public Health, 31, 85-91.

Kumar, S., Fischer, J., Robinson, E., et al (2007) Burnout and job satisfaction in New Zealand psychiatrists: a national study. International Journal of Social Psychiatry, 53, 306-316.

Wolfberg, E. (2003) [Social crisis and occupational fatigue among health professionals: warnings and resources.] Vertex, 14, 268-279.

Wolfberg, E., Heumann, G., Mazzella, L., et al (2005) [Problems and resources among hospital physicians, residents, and nurses in their hospital work.] Vertex, 16, 5-12.

\title{
Training on the management of depression in primary care in Azerbaijan
}

\section{Fuad Ismayilov' and Sevil Asadova ${ }^{2}$}

1'Department of Psychiatry, Azerbaijan Medical University, email fuadismayilov@psychiatry.az; ${ }^{2}$ World Health Organization, Country Office, email AsadovaS@euro.who.int

n 2006, the Azerbaijan Ministry of Health and the World Bank launched the 6-year Health Sector Reform Project (HSRP). The principal goal of the Project is to prepare and implement a fundamental and comprehensive reform of the health system in Azerbaijan, including a major emphasis on strengthening the primary care system (Ministry of Health Project Implementation Unit, 2007). The project envisions the development of a new optimised system of services, with the integration of mental health into general healthcare. In the line of this process, the Public Health and Reform Centre (PHRC) of the Ministry of Health has developed evidence-based clinical practice guidelines on depression, for implementation within primary care (Ministry of Health, 2009). At the same time, representatives from the PHRC and the Departments of Psychiatry and Family Medicine of Azerbaijan Medical University, as well as the State Institute for Advanced Training of Physicians (in cooperation with the World Health Organization Country Office), formed a task force to carry out a survey to assess the need for education in mental health for primary care doctors. A total of 308 primary care doctors (see Table 1) working in 14 settings in different regions of the country were randomly selected and interviewed by the research team.

All participants of the survey were asked to fill in a specially designed semi-structured questionnaire consisting of 34 items. Along with items covering personal information and professional responsibilities, the questionnaire included a set of questions about the recognition and treatment of depression in primary care. In addition, it queried the respondents' opinions and expectations regarding improvements in care provision for patients with depression. 
Table 1 Demographic data of the survey respondents $(n=308)$

$\begin{array}{lc} & \text { Number (\%) of participants } \\ \begin{array}{l}\text { Setting location } \\ \text { urban area } \\ \text { rural area }\end{array} & 186(60.4) \\ & 122(39.6) \\ \text { Gendera } & \\ \text { male } & \\ \text { female } & 138(45.1) \\ & 168(54.9) \\ \text { Age (years) } & \\ \text { up to } 30 & 15(4.9) \\ 31-40 & 39(12.7) \\ 41-50 & 89(28.8) \\ 51-60 & 122(39.6) \\ 61 \text { and over } & 43(14.0) \\ & \\ \text { Years in practice } & \\ \text { less than } 6 & 25(8.1) \\ 6-10 & 16(5.2) \\ 11-20 & 78(25.3) \\ 21-30 & 116(37.7) \\ \text { over } 30 & 73(23.7) \\ \end{array}$

aData not recorded in two instances.

\section{Recognition of depression in primary care}

According to international studies, the median prevalence rate for depression around the world is more than $10 \%$ in primary care settings (Üstün \& Sartorius, 1995). The data obtained from the survey revealed that less than $3 \%$ of the population presenting to primary care were recognised as suffering from depression. Although detection rates of depression varied between the different primary care settings, it may be proposed that the vast majority of sufferers are not being identified at the primary care level. In fact, primary care physicians have the difficult task of detecting depression among persons who are applying for services other than psychiatric treatment. Furthermore, patients with depression often present to primary care physicians with somatic symptoms such as poor appetite, weight loss, sleeplessness, fatigue and pain, which may be confused with physical illness. In addition, primary care physicians are highly likely to have patients with dual diagnoses - somatic illness and comorbid depressive disorder - which, in turn, may significantly extend the disability in these patients. In such cases, physicians often attribute the 'presenting' depression to the physical illness; thus they consider them as psychological responses secondary to a wide variety of underlying health conditions. Both patients and their doctors tend to 'normalise' depressive symptoms as variations of normal mood swings, and thus the prevalence of depression is underestimated (Ismayilov, 2004).

Even when recognised, the type and severity of depressive episodes are not always identified in accordance with the ICD-10 diagnostic criteria. In the present survey, $68 \%$ of primary care physicians could identify patients suffering from severe depression, but mild or moderate depressive episodes, as well as depression with atypical features, would generally remain undetected. Furthermore, 54\% of primary care physicians were unaware of bipolar depression and they never asked patients about a history of manic episodes.
Similarly, approximately only $15 \%$ of primary care physicians confirmed that they routinely assessed risk of suicide in patients recognised as having depression.

\section{The treatment of depression in primary care}

Despite the availability of clinical practice guidelines on the diagnosis and treatment of depression, primary care doctors have often treated them as academic reference materials, and have been slow to implement their recommendations. Although many patients receive treatment from primary care physicians, there is a lack of evidence that treatment is provided in effective doses and for adequate periods of time.

In the survey, $30 \%$ of primary care physicians reported prescribing antidepressants in their practice. Most of these tended to treat their patients with older classes of drugs, such as tricyclic antidepressants, and only $18.5 \%$ prescribed the newer selective serotonin reuptake inhibitors (SSRIs) and serotonin-noradrenaline reuptake inhibitors (SNRIs), which have been shown to be better tolerated than older classes of drug. In general, physicians demonstrated insufficient awareness of safety profile, side-effects and drug-drug interactions of the psychotropic medicines they prescribed. Therefore, many primary care doctors tend to administer very low (i.e. ineffective) doses of antidepressants. They have misconceptions about dosage regimens and rarely focus on adherence issues. Although the guidelines on depression stipulate at least 6 months of maintenance treatment, this period often does not exceed 2 months in primary care, as medication is discontinued after any initial improvement in depressive symptoms.

In some primary care settings the majority of physicians prescribe tranquillisers (benzodiazepines) rather than antidepressants as the first-line treatment for depression. Moreover, $21.9 \%$ of physicians who treat depression reported treating it with other medications (e.g. neuroleptics, nootropics and herbal medications) that are not indicated for depression. At the same time, psychological interventions that are effective for depression, such as counselling, cognitive-behavioural therapy, family therapy and interpersonal therapy, are not familiar to most physicians and are not used at primary care level.

In addition, currently in Azerbaijan there is no system in place to monitor or supervise the psychopharmacological or other mental health treatment approaches of primary care physicians.

\section{Training primary care doctors in the management of depression}

The problems in the recognition and treatment of depression are caused by inadequate training of primary care physicians, which is often limited to information obtained at the undergraduate level. Moreover, their training in mental health is based within psychiatric institutions and focuses on severe and complicated mental disorders, rather than on the mental health problems commonly encountered in primary care settings. The postgraduate programme for general 
practitioners that follows graduation from medical university does not include a mental health rotation. In our survey, only $2.3 \%$ of primary care physicians had had any postgraduate training in mental health.

In order to prepare primary care practitioners to provide services for patients with depression, ten master trainers from regional primary healthcare settings have been selected and educated to teach primary care doctors. The training is supervised by mental health professionals employed by Health Sector Reform Project Implementation Unit and is based on the Educational Programme on Depressive Disorders of the World Psychiatric Association (Maj et al, 2009), which has four modules:

O overview and fundamental aspects of depression

O physical illness and depression

O depression in specific population groups

o methods of training and education about depression.

The trainees learn general information about depression (epidemiology, clinical features, natural course and outcomes), application of the bio-psychosocial approach to depression, and contemporary classification of depressive disorders. Practical skills in the management of depressive disorders include their recognition, diagnosing depression with the Patient Health Questionnaire (PHQ-9), suicide risk assessment, developing a treatment plan, administering non-pharmacological interventions and antidepressant medications, and referral to specialist care. An emphasis was placed on addressing specific needs of patients (pregnancy, developmental aspects, ageing and comorbid physical illness). Doctors in training should develop proper attitudes towards interpersonal functioning, suicidal ideation and adherence to treatment on the part of patients with depression. An important aspect of the training are the methods of teaching primary care doctors, which include case presentations, role-play, small-group discussions and evaluation of knowledge, skills and attitudes.

Along with this short-term training for already employed primary care doctors, the Department of Psychiatry, Azerbaijan Medical University, in cooperation with the World Health Organization Country Office, has introduced a training programme on the management of depression for graduates in primary care. It is expected that training of primary care doctors on the management of depression will result in the development of whole-person care, reduce the stigma accompanying mental illness and improve access to care for the most vulnerable population groups.

\section{References}

Ismayilov, F. (2004) Cultural perspective of depressive disorders in Azerbaijan: a qualitative study. Azerbaijan Journal of Psychiatry, 9, 53-67.

Maj, M., Sartorius, N., Tasman, A., et al (eds) (2009) The WPA Educational Programme on Depressive Disorders (Revision of 2008). World Psychiatric Association.

Ministry of Health (2009) Clinical Guidelines on Diagnostics and Treatment of Depression. Ministry of Health.

Ministry of Health Project Implementation Unit (2007) Health Facility Survey Baseline Study Report. Ministry of Health.

Üstün T. B. \& Sartorius, N. (1995) Mental Illness in General Health Practice: An International Study. Wiley.

\title{
Global child mental health: what can we learn from countries with limited financial resources?
}

\author{
Norbert Skokauskas MD PhD and Myron Belfer BA MD AM MPA
}

Department of Psychiatry, Children's Hospital Boston, Harvard Medical School, MA, USA, email n_skokauskas@yahoo.com

\begin{abstract}
n 1977 the World Health Organization recommended that every country throughout the world should have a national plan for child mental health. The United Nations Convention on the Rights of the Child has been another important stimulus for child mental health policies and services in many countries. Adopted unanimously by the United Nations General Assembly in 1989 and instituted as international law in 1990, the Convention is an agreement on the basic protections that should be accorded to children. Adopted in 1961, the European Social Charter is
\end{abstract}

the major European treaty that secures children's rights. In 1996 the Charter was revised and expanded to include a list of core obligations of the contracting parties relating to the recognition of social, legal and economic rights for children and young persons.

These three international initiatives stimulated governments worldwide to develop national child and adolescent mental health policies and legislation. The presence of informed, effective policy is critically important for the mental health of children. Without guidance on the development of child 